\title{
A citizen perspective on nutritional warnings as front-of-pack labels: insights for the design of accompanying policy measures
}

\author{
Gastón Ares $^{1, *}$, Jessica Aschemann-Witzel ${ }^{2}$, María Rosa Curutchet ${ }^{3}$, Lucía Antúnez ${ }^{1}$, \\ Ximena Moratorio ${ }^{4}$ and Isabel Bove ${ }^{4}$ \\ 'Sensometrics \& Consumer Science, Instituto Polo Tecnológico de Pando, Facultad de Química, Universidad de la \\ República, By Pass de Rutas 8 y 101 s/n, CP 91000, Pando, Canelones, Uruguay: ${ }^{2}$ MAPP Centre for Research on \\ Customer Relations in the Food Sector, Aarhus University, Aarhus, Denmark: ${ }^{3}$ Observatorio de Seguridad \\ Alimentaria y Nutricional, Instituto Nacional de Alimentación, Montevideo, Uruguay: ${ }^{4}$ Ministerio de Salud Pública \\ 18 de julio 1892, Montevideo, Uruguay
}

Submitted 12 February 2018: Final revision received 15 June 2018: Accepted 13 July 2018: First published online 29 August 2018

\begin{abstract}
Objective: Nutritional warnings have recently been suggested as a simplified front-of-pack nutrition labelling scheme to facilitate citizens' ability to identify unhealthful products and discourage their consumption. However, citizens' perspective on this policy is still under-researched. The objective of the present work was to study how citizens perceive nutritional warnings and to evaluate public support of this policy, with the goal of deriving recommendations for the design of policy measures accompanying the introduction of nutritional warnings.

Design: An online survey with 1416 Uruguayan citizens, aged 18-75 years, 61\% female, was conducted. Participants had to answer a series of questions (openended and multiple-choice) related to their perception of warnings as a front-ofpackage nutrition labelling scheme.

Results: Participants showed a positive attitude towards nutritional warnings, which were regarded as easy to understand and to identify on food packages. The majority of respondents emphasized that they would take nutritional warnings into account when making their food choices, stating that they would allow them to make informed choices and, consequently, to increase the quality of their diet and their health status. Health motivation appeared as a crucial driver for taking nutritional warnings into consideration.

Conclusions: A high level of public support for nutritional warnings was observed. Responses can be used to derive a range of recommendations for a policy mix that should synergistically support the introduction of nutritional warnings and encourage citizens to take them into account when making their food purchases.
\end{abstract}

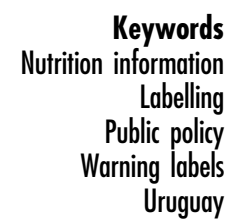

Front-of-pack (FOP) nutrition labelling has been developed in an attempt to provide simple visual cues that empower citizens to quickly and easily identify unhealthful food products and encourage more healthful choices $^{(1,2)}$. Various FOP labelling schemes that differ in the type of information they provide, and particularly in the degree to which they assist citizens to judge product healthfulness, exist ${ }^{(3)}$. Directive schemes provide an overall evaluation of product healthfulness and have been reported to be the most effective in helping consumers to accurately evaluate product healthfulness and encouraging changes in their food choices ${ }^{(3-8)}$. Several directive FOP nutrition labelling schemes have been developed worldwide, including the Nordic Keyhole ${ }^{(9)}$, the Australian
Health Star Rating ${ }^{(10)}$, the French five-colour nutrition label $(5-\mathrm{CNL})^{(11)}$ and nutritional warnings ${ }^{(12)}$.

Nutritional warnings have recently been implemented in Chile, where products should include black octagonal signs when their content of energy ('calories'; i.e. kilocalories, $1 \mathrm{kcal}=4.184 \mathrm{k}$ ), sugar, saturated fat or sodium exceed predetermined criteria ${ }^{(13)}$, therewith constituting a food with an 'imbalance'. In the Latin American context, this scheme seems particularly appropriate given the high availability of ultra-processed products with unfavourable nutrient profile in the current food market environment ${ }^{(14-16)}$. Consumption of ultra-processed products has shown the sharpest growth in middle- and low-income countries, partly due to the strong presence of such foods 
in the marketplace and increased income of citizens from low- and middle socio-economic level ${ }^{(16,17)}$.

Ultra-processed foods are usually cheap and are heavily promoted by intense marketing campaigns ${ }^{(15)}$. For this reason, lower socio-economic groups are particularly vulnerable to these foods due to the high relative importance they attach to price in their decision-making process, their lack of literacy needed to interpret marketing claims and their lack of nutritional knowledge ${ }^{(16,18-20)}$. In this sense, recent research has shown that adults and children from low socio-economic level have a more positive attitude towards and are less critical towards labels of ultra-processed foods than those from middle and high socio-economic level ${ }^{(20,21)}$. This situation requires attention of policy makers as it constitutes a case of vulnerable consumer groups not being able to make informed choices $^{(22)}$.

Research on the ability of nutritional warnings to encourage more healthful food choices is still limited, as is research on citizens' perception of this scheme. Therefore, assessment of how citizens perceive and interpret nutritional warnings is highly relevant for policy makers in countries considering adopting this type of scheme to encourage their citizens to make more healthful food choices.

The breadth of research on FOP nutrition labelling schemes has shown that their effect should be expected to be minor if consumers are not familiarized with them ${ }^{(23-25)}$. These studies provided evidence that FOP nutrition labelling needs to be accompanied by communication campaigns. Such campaigns can provide information about how to use the labelling scheme, guide interpretation and encourage citizens to take nutrition labelling into account in their food choices.

Behaviour change theories typically suggest that several factors or triggers need to be given to achieve the desired change ${ }^{(26)}$. Therefore, communication strategies should aim at 'reaching' the citizen repeatedly and in various ways to encourage changes in their purchase decisions ${ }^{(27,28)}$. Efforts destined to encourage citizens to use FOP nutrition labelling should be accompanied with other policy measures aimed at supporting behaviour change or constituting a different communication channel, to allow for repeated contact and variation of the message and context.

The design of communication campaigns and other accompanying policy measures should be preceded by an in-depth understanding of citizens' perception. This approach has been highlighted as useful for the adoption of other policies to support dietary behaviour change ${ }^{(29)}$. Insights on citizens' perspective and behaviour can provide a useful input for the design of successful strategies during the implementation of this public policy, to increase awareness more effectively and encourage widespread use of FOP nutrition labels. However, research on consumer perception and reaction to nutritional warnings is still limited. In particular, no published research has been found exploring citizens' perception and interpretation of this FOP nutrition labelling scheme.
Citizen perception of public policies is shaped by sociodemographic variables ${ }^{(30,31)}$. In the specific case of nutrition labelling, prior research has shown that gender, age and socio-economic level modulate the ability of FOP labels to modify food choices due to differences in nutrition knowledge and the relative importance attached to the nutritional composition of foods in daily purchase decisions ${ }^{(32,33)}$. In particular, socio-economic level has been identified as one of the main variables influencing how people choose and perceive food products ${ }^{(34,35)}$. Therefore, this variable is expected to largely influence interpretation of FOP nutrition labelling schemes, as well as their impact on food choices. For this reason, the identification of citizen segments with different perception of nutritional warnings can contribute to the development of targeted communication strategies that effectively encourage people to take nutritional warnings into account when making their food choices ${ }^{(25)}$ and aid the choice of the best accompanying policies.

In this context, the aims of the present work were to: (i) explore how citizens perceive nutritional warnings and how they expect to react to them; (ii) evaluate public support of this public policy; and (iii) evaluate sociodemographic differences in perception of and reaction to nutritional warnings. Results from the present work are expected to deepen understanding of how citizens perceive nutritional warnings and to provide recommendations for the design of policy measures accompanying their introduction.

\section{Materials and methods}

The study was conducted in Uruguay, a country located in the south-east of South America with one of the highest rates of overweight and obesity (64.9\%) on the continent ${ }^{(36)}$, and in a time of a political debate on the implementation of nutritional warnings as a public policy to tackle the obesity epidemic $^{(37)}$. An online survey was implemented to explore Uruguayan citizens' perception of nutritional warnings using open-ended and multiple-choice questions. The decision to conduct the study online was made based on the large penetration of the Internet in Uruguay, which reached $88 \%$ of the population older than 10 years old in $2017^{(38)}$. Considering that $94 \%$ of adult Uruguayan Internet users have a Facebook account ${ }^{(38)}$, the survey was targeted exclusively to Facebook users. The selected sampling frame can be considered as fairly representative of the Uruguayan population.

\section{Participants}

A sample of 1416 people was recruited using a Facebook advertisement targeted at Uruguayan Facebook users older than 18 years. The advertisement was available during a two-week period in June 2017. During recruitment, participants were invited to participate in a study related to food labels conducted by Universidad de la República. No incentives were provided to participants. The study was anonymous, and no personal or sensitive data were collected. 
The sample was randomly drawn from a much larger respondent group of 4300 respondents who had completed the survey, to arrive at a sample which represents the share of the different socio-economic groups in the population. Socio-economic level was estimated using the methodology proposed by the Centro de Investigaciones Económicas ${ }^{(39)}$. The quota sampling aimed at a distribution of $20 \%$ respondents of low and high status, respectively, and 60\% of middle status. The characteristics of the participants included in the final sample are summarized in Table 1.

\section{Questionnaire}

The survey was administered online using Compusense Cloud (Compusense Inc., Guelph, ON, Canada) and was divided into three main sections. The first section consisted of two open-ended questions and one closed question about participants' perception of and expected reaction to nutritional warnings. Participants were presented with the following text: 'The Ministry of Health is evaluating the inclusion of complementary information about the nutritional composition of packaged foods. Products with excessive content of sugar, fat and salt should include warnings (as those shown in the Figure) in the front of their package', accompanied with the design of the warnings (Fig. 1). They were asked to freely note down their opinion about the proposal. No word limit was implemented. Then, respondents were asked to indicate what they would do if they went to the supermarket and saw one of the products they usually buy, but containing

Table 1 Sociodemographic characteristics of the participants: Uruguayan citizens aged $18-75$ years $(n 1416)$ who responded to an online survey about nutritional warnings as front-of-pack labels, 2017

\begin{tabular}{lc}
\hline Characteristic & \% of participants \\
\hline Gender & \\
Female & 61 \\
Male & 39 \\
Age (years) & \\
$18-24$ & 16 \\
$25-34$ & 35 \\
$35-49$ & 34 \\
$50-65$ & 12 \\
$>65$ & 3 \\
Educational level & \\
Primary education & 9 \\
Secondary education & 43 \\
Technical education & 26 \\
University degree & 15 \\
Postgraduate studies & 7 \\
Socio-economic level & \\
Low & 20 \\
Medium & 60 \\
High & 20 \\
Number of people in the household & \\
1 & 26 \\
2 & 26 \\
3 & 39 \\
$\geq 4$ & \\
\hline
\end{tabular}

*Socio-economic level was estimated using the methodology proposed by Centro de Investigaciones Económicas ${ }^{(39)}$. nutritional warnings, using a multiple-choice question with the following options: 'I would keep buying the same product', 'I would buy a product of the same category with fewer warnings', 'I would buy a product of the same category without warnings' and 'I would refrain from buying the product category'. After selecting their response, they had to explain the motives for doing so by answering an open-ended question.

The second section aimed at evaluating support of the warning scheme using statements related to attitudes towards the scheme and assessment of helpfulness and potential advantages. Participants were asked to indicate their degree of agreement with nine statements (Table 2) using a five-point Likert agreement-disagreement scale ( 1 = 'completely disagree', 5='completely agree'). The third section contained a series of sociodemographic questions.

\section{Data analysis}

\section{Qualitative analysis of open-ended questions}

An exploratory approach was used to analyse the openended questions. Responses to the open-ended questions were analysed using content analysis following an inductive coding approach ${ }^{(40)}$. Responses were classified into themes by one of the researchers and verified by an additional researcher. The same procedure was used to classify the content of the responses included within each of the themes into sub-themes. Frequency of mention of each sub-theme/theme was determined by counting the number of participants who mentioned words within that sub-theme/theme and expressed as percentage.

\section{Descriptive and quantitative analysis of multiple-choice questions and attitude and perception statements}

Perception of and reaction to the warnings was assessed by analysing the multiple-choice question and by inspecting the degree of agreement to the statements related to attitudes towards and assessment of the warnings. Responses to the Likert scales of the second section of the questionnaire were analysed using descriptive statistics. Differences in perception of warnings between gender, age and socioeconomic status were evaluated using the $\chi^{2}$ test.

\section{Results}

The results are presented in the order of the sections of the survey; that is, first, the results of participants' assessment

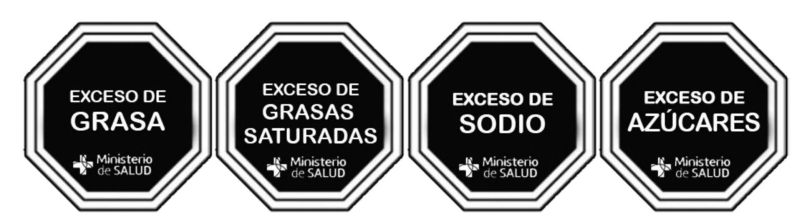

Fig. 1 Design of the nutritional warnings highlighting excessive content of fat, saturated fat, sodium and sugars (from left to right) 
Table 2 Percentage of participants who agreed and disagreed with statements related to nutritional warnings and mean score (with standard deviation): Uruguayan citizens aged $18-75$ years $(n 1416), 61 \%$ female, who responded to an online survey about nutritional warnings as front-of-pack labels, 2017

\begin{tabular}{|c|c|c|c|c|}
\hline Statement & Mean score* & $\mathrm{SD}$ & $\begin{array}{l}\% \text { of participants } \\
\text { who agreed }\end{array}$ & $\begin{array}{l}\% \text { of participants } \\
\text { who disagreed }\end{array}$ \\
\hline 1. It is a good policy & 4.6 & 0.7 & 95.4 & $2 \cdot 1$ \\
\hline 2. It is a useless policy & 1.6 & 0.9 & 4.6 & $90 \cdot 3$ \\
\hline 3. It would help me improve the quality of my diet & 4.3 & 0.9 & $86 \cdot 4$ & 4.4 \\
\hline 4. I would not take them into account to choose my foods & $1 \cdot 6$ & 0.8 & 4.2 & $91 \cdot 0$ \\
\hline 5. It would help me to clearly identify unhealthful products & 4.5 & 0.7 & 94.0 & 3.0 \\
\hline $\begin{array}{l}\text { 6. It would allow me to know better the nutritional } \\
\text { composition of the products I buy }\end{array}$ & 4.3 & 0.9 & $87 \cdot 1$ & $5 \cdot 2$ \\
\hline $\begin{array}{l}\text { 7. I would take the warnings into account to choose the } \\
\text { foods I buy }\end{array}$ & 4.5 & 0.7 & 93.8 & 2.5 \\
\hline 8. It would help improve the health status of the population & 4.3 & 0.9 & $84 \cdot 8$ & 3.7 \\
\hline $\begin{array}{l}\text { 9. It is necessary to improve the quality of the diet of } \\
\text { Uruguayans }\end{array}$ & 4.4 & 0.8 & $89 \cdot 1$ & 3.4 \\
\hline
\end{tabular}

`Scores were measured on a five-point Likert scale ( $1=$ 'completely disagree', $5=$ 'completely agree').

of nutritional warnings, and second, assessment of sociodemographic differences.

\section{Consumers' perception of nutritional warnings}

Content analysis of the open-ended question exploring participants' opinion about nutritional warnings identified a total of seven themes: general attitude, advantages, expected positive consequences, factors conditioning success, reasons for the implementation, disadvantages and additional policies. For each of the themes, subthemes were identified. Themes, sub-themes and examples of individual responses are shown in Table 3.

The great majority of participants (95.3\%) described their general attitude towards the policy as mostly positive. Only $2.2 \%$ of the participants perceived nutritional warnings as negative.

Participants stressed a series of advantages of nutritional warnings: they are easy to understand, they would facilitate decision making and they would enable informed choices. Participants also stressed that warnings would be easy to identify on food labels and would quickly capture their attention, encouraging them to consider nutrition information in their decision making. Some of the participants $(1.0 \%)$ also stated that this type of visual sign would be in 'competition' with the marketing strategies of food companies, minimizing the influence of the latter on their food choices.

The expected positive consequences of the implementation of nutritional warnings were highlighted by $15.9 \%$ of the participants. As shown in Table 3, the most frequently mentioned expected consequence was related to raising awareness about the nutritional composition of foods. Participants also thought that the implementation of this type of FOP label would encourage people to make more healthful choices and, in turn, improve the health status of the population. Warnings were also regarded as an educational tool, particularly for vulnerable groups, such as people with low nutritional knowledge and children. Some of the participants stated that warnings would be useful for them to teach their children about food healthfulness and which foods they should infrequently eat. Another expected positive consequence derived from the implementation of the warnings was food reformulation. A proportion, albeit small, of the participants indicated that nutritional warnings would encourage food companies to reformulate their products and to develop more healthful foods.

Participants discussed factors conditioning the success of the policy, which were mainly related to the characteristics of the warnings and their implementation (Table 3). Participants referred to the size of the warnings and stressed that they should be large in size to ensure easy identification. They also indicated that warnings should be compulsory on all packaged foods, that implementation should be quick and that the government should implement strict controls. Participants mentioned the need to accompany the implementation of the warnings with communication campaigns that raise awareness, explain how to interpret the warnings, and clearly communicate the risks associated with the consumption of sugar, fat and sodium. A small share of participants suggested changes to the warnings to increase their efficacy. As shown in Table 3, $2.0 \%$ of the participants suggested changes in the design of the warnings, mainly their colour and shape, whereas $0.9 \%$ stated that quantitative information about nutrient content should also be included in the warnings to facilitate comparison among products.

Reasons for the implementation of the warnings were mentioned in the responses to the open-ended question, which were mainly related to the need to rely on simple and trustworthy information. Participants referred to the difficulties they experience when trying to find and understand conventional back-of-pack nutrition information. They also stressed that food companies frequently use deceptive marketing strategies to convey the idea that certain products are healthful. Information was regarded as a citizen right and 
Table 3 Themes, sub-themes and example(s) of individual responses identified in the open-ended questions in which participants wrote down their opinion about nutritional warnings, and the percentage of participants who mentioned each theme and sub-theme: Uruguayan citizens aged 18-75 years ( $n$ 1416), $61 \%$ female, who responded to an online survey about nutritional warnings as front-of-pack labels, 2017

\begin{tabular}{|c|c|c|c|}
\hline Theme & Sub-theme & Example(s) of individual responses & $\begin{array}{l}\text { Frequency of } \\
\text { mention }(\%)\end{array}$ \\
\hline \multirow[t]{4}{*}{ General attitude } & & & $95 \cdot 3$ \\
\hline & Positive attitude & 'It is a good initiative'; 'An excellent idea' & 93.1 \\
\hline & Indifference & 'I don't care'; 'It won't change what I eat' & $0 \cdot 1$ \\
\hline & Negative attitude & 'Absurd'; 'A bad idea. If a food is not healthful it should not be sold' & $2 \cdot 2$ \\
\hline \multirow[t]{6}{*}{ Advantages } & & & $32 \cdot 9$ \\
\hline & Easy to understand & $\begin{array}{l}\text { 'We should know what we eat and those who don't know about nutrition find it very difficult to understand the labels'; } \\
\text { 'Very useful to facilitate understanding of nutrition information at the time of purchase' }\end{array}$ & 8.8 \\
\hline & Enables informed choices & 'It would help people to make informed choices and eat more healthfully' & $8 \cdot 3$ \\
\hline & Facilitates decision making & $\begin{array}{l}\text { 'Given the number of similar products available in the marketplace, it would facilitate decision making and choice of } \\
\text { healthful products' }\end{array}$ & $7 \cdot 8$ \\
\hline & $\begin{array}{l}\text { Easy to identify/captures } \\
\text { attention }\end{array}$ & $\begin{array}{l}\text { 'It would be very easy to identify and to know more about a product'; 'They would be seen quickly and easily'; 'They } \\
\text { would definitely catch my attention' }\end{array}$ & $7 \cdot 0$ \\
\hline & It counters marketing strategies & $\begin{array}{l}\text { 'Visual signs to compete with marketing is what we need'; 'They would counteract deceitful advertising'; 'To prevent } \\
\text { advertising lies that poison us' }\end{array}$ & $1 \cdot 0$ \\
\hline \multirow{5}{*}{$\begin{array}{l}\text { Expected positive } \\
\text { consequences }\end{array}$} & & & $15 \cdot 9$ \\
\hline & Raises consciousness & $\begin{array}{l}\text { 'It would make people more conscious of what they eat'; 'It's an invitation to care about what we consume and the } \\
\text { damage it causes us'; 'People will be shocked about some products' }\end{array}$ & $6 \cdot 4$ \\
\hline & $\begin{array}{l}\text { Encourages more healthful food } \\
\text { choices }\end{array}$ & 'It would help us make more healthful choices' & $3 \cdot 3$ \\
\hline & $\begin{array}{l}\text { Improves the health status of the } \\
\text { population }\end{array}$ & 'It will help us have a more healthful life'; 'It would contribute to the prevention of several diseases' & 3.4 \\
\hline & Educates people & $\begin{array}{l}\text { 'It is a good way to educate people'; 'It would educate those who have no idea about nutrition'; 'It would help us } \\
\text { educate our children' }\end{array}$ & 1.6 \\
\hline \multirow{8}{*}{$\begin{array}{l}\text { Factors conditioning } \\
\text { success }\end{array}$} & Encourages food reformulation & 'This would encourage brands to invest their money in making healthful products' & $\begin{array}{r}1 \cdot 2 \\
14 \cdot 2\end{array}$ \\
\hline & Communication campaigns & $\begin{array}{l}\text { 'It should be accompanied by communication campaigns from primary school'; 'This should be accompanied by a } \\
\text { huge communication campaign stressing the risks associated with these products' }\end{array}$ & $3 \cdot 6$ \\
\hline & Large size & 'They should be big, so that we can easily read them' & 3.5 \\
\hline & Changes to the design & 'I would use bright and attention-grabbing colours' & $2 \cdot 0$ \\
\hline & Governmental control & 'It requires strict control'; 'Companies should be controlled' & 1.9 \\
\hline & Compulsory implementation & 'It should be compulsory'; 'It should be included in all foods with excessive content' & 1.3 \\
\hline & Include additional information & 'It should include how much they contained'; 'Quantities should be included' & 0.9 \\
\hline & Quick implementation & 'It's an urgent measure!'; 'It should have already been implemented' & 0.9 \\
\hline \multirow{4}{*}{$\begin{array}{l}\text { Reasons for the } \\
\text { implementation }\end{array}$} & & & $13 \cdot 1$ \\
\hline & $\begin{array}{l}\text { Nutrition information is difficult to } \\
\text { find and understand }\end{array}$ & $\begin{array}{l}\text { 'Information about how much quantity products contain is not enough to clearly evaluate whether they are healthful or } \\
\text { not'; 'Nowadays we do not understand the information or it is not easily accessible' }\end{array}$ & $6 \cdot 9$ \\
\hline & $\begin{array}{l}\text { Health problems of the } \\
\text { population }\end{array}$ & 'It is necessary given the serious health problems of the Uruguayan population' & $3 \cdot 0$ \\
\hline & $\begin{array}{l}\text { Deceitful marketing strategies } \\
\text { Information is a consumer right }\end{array}$ & $\begin{array}{l}\text { 'Many products are advertised as healthful but they are not'; 'The market is full of deceitful marketing strategies' } \\
\text { 'It would help us realize our citizens' rights' }\end{array}$ & $\begin{array}{l}2 \cdot 3 \\
0.9\end{array}$ \\
\hline
\end{tabular}




\begin{tabular}{|c|c|c|c|}
\hline Theme & Sub-theme & Example(s) of individual responses & $\begin{array}{l}\text { Frequency of } \\
\text { mention (\%) }\end{array}$ \\
\hline \multirow{12}{*}{ Disadvantages } & & & 8.7 \\
\hline & $\begin{array}{l}\text { It does not include quantitative } \\
\text { information }\end{array}$ & 'It is necessary to have information about quantity' & $2 \cdot 7$ \\
\hline & $\begin{array}{l}\text { Criteria for defining 'excess' are } \\
\text { not clear }\end{array}$ & $\begin{array}{l}\text { 'What is the criteria for considering excess?'; 'I don't understand how to interpret "excess"? Excess compared to } \\
\text { what?' }\end{array}$ & 2.4 \\
\hline & $\begin{array}{l}\text { It does not consider positive } \\
\text { nutrients }\end{array}$ & $\begin{array}{l}\text { 'Information should be included on both "good" and "bad" products'; 'I would also highlight positive things. For } \\
\text { example, vitamins, minerals, low in sodium' }\end{array}$ & 0.8 \\
\hline & It scares & $\begin{array}{l}\text { 'These signs would scare people so that they do not consume those products'; 'The signs are too negative. I would } \\
\text { say aggressive' }\end{array}$ & 0.7 \\
\hline & $\begin{array}{l}\text { The information is already } \\
\text { available on the labels }\end{array}$ & 'Nutrition information is enough'; 'It isn't necessary to include these signs. Nutrition information is already complete' & 0.6 \\
\hline & $\begin{array}{l}\text { It does not include non-packaged } \\
\text { products }\end{array}$ & 'What happens with the products that are sold in a takeaway or consumed in a restaurant?' & 0.4 \\
\hline & It is confusing & 'It is more confusing than informative'; 'It can create confusion in people without nutrition education' & 0.3 \\
\hline & It does not educate consumers & 'It does not pursue the objective of educating people'; 'It does not educate consumers' & 0.2 \\
\hline & It would reduce sales of products & 'What would happen with small shops when sales of these products decrease?' & 0.4 \\
\hline & $\begin{array}{l}\text { It does not allow to compare } \\
\text { products }\end{array}$ & 'It does not allow me to compare products' & 0.1 \\
\hline & $\begin{array}{l}\text { It encourages unhealthful } \\
\text { reformulation }\end{array}$ & $\begin{array}{l}\text { 'My great fear is related to producers. For example, they could replace sugar for other substances that can be even } \\
\text { more harmful for our body' }\end{array}$ & 0.1 \\
\hline \multirow[t]{6}{*}{ Additional policies } & & & $14 \cdot 7$ \\
\hline & Additional labelling policies & 'It is urgent to label GMO'; 'It would be nice to have labels for products that contain gluten and dairy' & $13 \cdot 1$ \\
\hline & $\begin{array}{l}\text { Regulation of marketing } \\
\text { practices }\end{array}$ & 'Advertising of these substances should be prohibited' & 0.8 \\
\hline & Prohibition of specific products & 'These products with excess should be prohibited' & 0.6 \\
\hline & Taxes and subsidies & 'It is not enough. Healthful foods should be subsidized and unhealthful products should pay more taxes' & $0 \cdot 1$ \\
\hline & $\begin{array}{l}\text { Promote consumption of natural } \\
\text { products }\end{array}$ & 'Policies should aim at encouraging people to consume fresh home-made foods' & $0 \cdot 1$ \\
\hline
\end{tabular}

GMO, genetically modified organisms.

GMO, genetically modified organisms.
Percentages do not sum up to $100 \%$ because each participant could give responses related to more than one sub-theme. 
warnings as a measure to enforce it. Participants also stressed that the implementation of nutritional warnings was necessary given the serious health problems related to overweight and obesity in the country.

A small proportion of participants (8.7\%) highlighted disadvantages of the policy. The most frequent concerns were related to the lack of quantitative information about nutrient content in the warnings and doubts regarding the criteria selected for classifying nutrient content as excessive. The rest of the disadvantages were mentioned by less than $1 \%$ of the participants (Table 3 ).

Finally, $14.7 \%$ of the participants indicated that additional policies should be implemented to promote healthy eating in the Uruguayan population (Table 3). These policies were mainly related to additional labelling policies: labelling of genetically modified foods (6.4\%), more salient information about additives and ingredients (3.0\%), and the inclusion of information about food allergens $(3.7 \%)$.

\section{Responses to statements related to the assessment of nutritional warnings}

As shown in Table 2, high public support for nutritional warnings was found. The great majority of the participants regarded nutritional warnings as a good policy (item 1; $95.4 \%$ ), whereas the percentage of participants perceiving the policy as 'useless' was markedly low (item 2; 4.6\%).

The great majority of the participants also showed a positive disposition to take the warnings into account for choosing their foods (items 4 and 7) and stated that the warnings would help them to clearly identify unhealthful products (items 5 and 6) and to improve the quality of their diet (item 3; Table 2). In addition, most of the participants agreed with the statements related to the positive effect of the warnings on the quality of the diet (item 9) and the health status of the Uruguayan population (item 8).

\section{Differences between sociodemographic groups in the assessment of nutritional warnings}

Support of the policy (Table 2) was not significantly affected by gender, age and socio-economic status, as evidenced by the non-significant differences in the frequency distribution of responses to items 1 and 2 $(P>0 \cdot 14)$. The influence of sociodemographic variables was also non-significant for the items related to the effect of nutritional warnings on the quality of the diet and the health status of the Uruguayan population (items 8 and 9; $P>0.45)$. In addition, gender, age and socio-economic status did not significantly $(P>0.09)$ influence participants' disposition to take nutritional warnings into account when choosing foods (item 7).

However, participants' perceived helpfulness of the warnings was significantly different for gender and socioeconomic status. The percentage of participants agreeing with item 3 ('It would help me improve the quality of my diet') was significantly higher $(P=0.026)$ among those from low socio-economic status (90\%) $v$. those from medium and high socio-economic status (86\% and $84 \%$, respectively). In addition, the percentage of participants who agreed that nutritional warnings would allow them to be more knowledgeable about the nutritional composition of the products they buy (item 6) increased significantly $(P=0.009)$ with age, from $83 \%$ for 18-24-year-old participants to $98 \%$ for participants older than 65 years.

Finally, willingness to take the warnings into account when choosing their foods (item 4, reversed) was significantly lower $(P=0.001)$ for 18-24-year-old participants compared with those in the other age groups: 88\% v. 91-93\%.

\section{Expected purchase behaviour after the implementation of the warnings}

When participants were asked what they would do if the product they usually buy was found to include warnings, the great majority indicated that they would modify their choice. As an explanation, they mainly referred to interest in health. As shown in Table 4, only $5.8 \%$ of the participants indicated that they would keep on buying the same product if it contained warnings. Reasons for not changing their choice were mainly related to already being aware of nutrition information, habits and infrequent consumption of unhealthful packaged foods (Table 4). However, 26.8\% of the participants who answered that they would keep buying the same product indicated that they would buy it less frequently if it contained warnings.

Among those participants who answered that they would modify their choice, substitution by a similar product without warnings was the most frequent option, followed by category abandonment and finally substitution by a similar product with fewer warnings (Table 4). However, it is important to highlight that some participants indicated that their decision would depend on the food category and the characteristics of the other products in the category. In general, these participants stressed that they would change their choice if the product was frequently consumed, whereas in the case of products that are infrequently consumed they would not make changes. Regarding the characteristics of the other products in the category, they indicated that apart from the number of warnings, they would also consider price, brand and sensory characteristics.

The most frequently mentioned reason for changing the product was related to interest in health and healthy eating, regardless of the type of change (Table 4). Some of the respondents highlighted that although they are interested in eating healthfully, they usually do not have access to sufficient information to evaluate whether products are healthful or not. Participants also indicated that once the warnings were implemented, they would have such information available and that they would be more conscious of their eating behaviour. This, in turn, would enable them to 
Table 4 Responses to the multiple-choice question 'What would you do if you went to the supermarket and saw one of the products you usually buy containing nutritional warnings?' and themes identified in the follow-up open-ended question about the motives for the response: Uruguayan citizens aged $18-75$ years $(n 1416), 61 \%$ female, who responded to an online survey about nutritional warnings as front-of-pack labels, 2017

\begin{tabular}{|c|c|c|}
\hline Response & Theme & Frequency (\%) \\
\hline \multirow[t]{6}{*}{ I would keep buying the same product } & & $5 \cdot 8$ \\
\hline & I am already aware of what I eat & 41.5 \\
\hline & I would eat the same product but less frequently & $26 \cdot 8$ \\
\hline & I am used to eating the products & 19.5 \\
\hline & I do not consume many unhealthful products & $9 \cdot 8$ \\
\hline & The information included in the warnings is not relevant & $9 \cdot 8$ \\
\hline \multirow[t]{9}{*}{ I would buy a product of the same category with fewer warnings } & & $19 \cdot 2$ \\
\hline & Interest in health/healthful products & 62.5 \\
\hline & $\begin{array}{l}\text { I would have the information to choose/l would be } \\
\text { conscious }\end{array}$ & $17 \cdot 6$ \\
\hline & I would choose better/better products & $12 \cdot 5$ \\
\hline & It depends on the product category & 8.5 \\
\hline & Trust in the policy/Ministry of Health & $5 \cdot 9$ \\
\hline & I would try to consume less sugar/fat/sodium & 4.8 \\
\hline & I would be able to make progressive changes in my food habits & 4.4 \\
\hline & $\begin{array}{l}\text { It depends on the characteristics of the other products } \\
\text { available in the marketplace }\end{array}$ & 4.4 \\
\hline \multirow{9}{*}{ I would buy a product of the same category without warnings } & & $45 \cdot 2$ \\
\hline & Interest in health/healthful products & $67 \cdot 0$ \\
\hline & $\begin{array}{l}\text { I would have the information to choose/l would be } \\
\text { conscious }\end{array}$ & $20 \cdot 8$ \\
\hline & It depends on the product category & 9.5 \\
\hline & I would choose better/better products & 8.4 \\
\hline & I would try to consume less sugar/fat/sodium & 3.3 \\
\hline & I would be able to make progressive changes in my food habits & 4.2 \\
\hline & $\begin{array}{l}\text { It depends on the characteristics of the other products } \\
\text { available in the marketplace }\end{array}$ & 2.8 \\
\hline & Trust in the policy/Ministry of Health & $2 \cdot 0$ \\
\hline \multirow[t]{10}{*}{ I would refrain from buying the product category } & & 29.8 \\
\hline & Interest in health/healthful products & 70.9 \\
\hline & It depends on the product category & $16 \cdot 8$ \\
\hline & I would choose better/better products & $7 \cdot 3$ \\
\hline & $\begin{array}{l}\text { It depends on the characteristics of the other products } \\
\text { available in the marketplace }\end{array}$ & $2 \cdot 4$ \\
\hline & Most products are identical & $2 \cdot 1$ \\
\hline & I would try to consume less sugar/fat/sodium & 1.9 \\
\hline & $\begin{array}{l}\text { I would have the information to choose/l would be } \\
\text { conscious }\end{array}$ & 3.3 \\
\hline & Trust in the policy/Ministry of Health & $2 \cdot 1$ \\
\hline & To educate my children & $1 \cdot 2$ \\
\hline
\end{tabular}

change their choice to a healthier product. Trust in the policy and the Ministry of Health was also mentioned by participants as a reason for altering their choice.

Some of the participants who answered that they would buy a different product within the same category indicated that such an approach would allow them to eat more healthfully without having to make radical changes in their food habits. In this sense, they indicated that warnings would allow them to make progressive changes by changing their habitually chosen product to a more healthful alternative as a first step, and then changing to an increasingly more healthful product in the same or in a different category.

\section{Discussion}

Nutritional warnings are a new type of FOP nutrition labelling scheme aimed at facilitating citizens' ability to identify unhealthful products and discourage their frequent consumption. The aim of the present work was to explore Uruguayan citizens' perception of this public policy in a multi-method approach. Results provided insights of value for the design of communication campaigns and other accompanying policies to increase awareness and encourage use of the warnings. The discussion of the results is structured around the two research questions addressed in the study.

\section{How do consumers perceive the nutritional warnings and expect to react to them, and which factors emerge as relevant for support for or opposition to the policy, from a citizen perspective?} Results showed a high level of public support for nutritional warnings, even when considering that responses to the Likert questions are likely to be affected by social desirability bias. A high level of support for the policy was also expressed in the open-ended questions 
(Table 3). This result is in accordance with previous studies conducted in Europe that report that nutrition labelling is typically one of the policies with the highest citizen acceptance ${ }^{(30,31)}$. Nutrition labelling has also been regarded as one of the policies with the lowest stakeholder opposition $^{(41)}$, which enables quick policy action.

The favourable attitude towards nutritional warnings can be explained by participants' positive evaluation of their salience, simplicity and ease of interpretation. These characteristics have been extensively recognized as key determinants of the efficiency of FOP nutrition labelling schemes ${ }^{(42-44)}$. In this sense, recent research has shown that nutritional warnings have advantages over Guideline Daily Amount and traffic-light systems in terms of processing speed and ability to modify perceived healthfulness of unhealthful products ${ }^{(4)}$.

The great majority of participants expressed willingness to take warnings into account when making their food purchase decisions. This implies that nutritional warnings have the potential to encourage more healthful food choices and improve the health status of the Uruguayan population. Interestingly, an analysis of the situation in Chile found that approximately half of Chilean consumers reported that nutritional warnings had influenced their food purchases one year after their compulsory introduction ${ }^{(45)}$.

According to participants' responses, within-category product substitution is the most likely effect of the implementation of nutritional warnings. Thus, the policy should be expected to encourage citizens to replace their usual products by more healthful alternatives but is not expected to cause radical changes in consumer eating patterns. Similar results have been recently reported in a simulated repeated purchase experiment ${ }^{(46)}$. In Chile, a similar finding has been observed in the real market setting: $67 \cdot 8 \%$ of the Chilean consumers who took warnings into account reported selecting products with fewer warnings ${ }^{(45)}$. These results suggest that product reformulation would be an efficient accompanying policy during the implementation of nutritional warnings, while also an interesting business opportunity for food companies. Evidence of the contribution of product reformulation to improving the health status of the population can be found in the UK's gradual sodium reduction programme ${ }^{(47)}$. Interestingly, participants indicated that they would rather choose foods with no warnings than foods with fewer warnings. This contrasts with the finding from Chile and might be explained by the fact that the availability of products with no warnings might be lower than consumers expect before the implementation of the policy, particularly in product categories characterized by high sugar, fat and/or sodium content.

The impact of nutritional warnings is expected to be category-dependent. According to participants' responses to the open-ended question, nutritional warnings are mainly expected to influence their purchase decisions of unhealthful products - such as those high in sugar, fat or sodium - and, in particular, of products with a deceptively healthful image, given that consumers would be more aware of their actual healthfulness. This is in agreement with results from experimental studies which show that interpretative nutritional labelling schemes mainly influence healthfulness perception of products with a positive healthful image ${ }^{(4,48,49)}$.

Interest in health was the most frequently mentioned motivation for willingness to consider the warnings in participants' decision-making process, which stresses the need to implement education programmes and communication campaigns targeted at increasing health concern and clearly communicating the health risks associated with excessive consumption of sugar, fat and sodium. Participants' responses to the open-ended question provided insights to the design of communication campaigns.

First, communication campaigns should inform citizens that nutritional warnings are available and clearly explain their meaning. Considering that lack of quantitative information and lack of understanding of the criteria underlying the definition of 'excess' were highlighted as disadvantages of nutritional warnings, it would be advisable to clearly explain the meaning of the expression 'excess of' in leaflets or a website specifically designed for this purpose. Second, communication campaigns should guide the interpretation of the warnings and encourage citizens to use them to make healthful food choices. Considering that respondents stressed that warnings would raise awareness of the nutritional composition of the foods they eat, references to awareness and conscious consumption in communication campaigns could positively contribute to increasing the impact of the policy. Third, communication campaigns should be based on the combined effect of multiple information channels and focus on increasing health motivation, stressing the need to prioritize health motives in food purchase, explaining the health effects of excessive consumption of sugar, fat and sodium and the rationale of nutritional warnings. In addition, the use of information channels instore could trigger health motivation at the time of purchase and motivate consumers to use nutritional warnings when making their purchase decisions. The efficiency of such an approach has recently been reported for increasing the efficiency of health logos and traffic lights ${ }^{(24,25)}$.

Finally, it is worth mentioning that trust in the policy and the Ministry of Health was recognized as a motivation for considering the nutritional warnings when purchasing foods. Trust in the messenger has been recognized as a relevant cue for trust in label information and the decision made as a result ${ }^{(50)}$. In this sense, the inclusion of a reference to the Ministry of Health in the warning sign could positively influence the efficiency of the policy.

\section{What sociodemographic differences exist in perception of and reaction to the nutritional warnings?}

Previous research has shown that sociodemographic characteristics, such as age, gender and socio-economic 
status, influence use of nutrition information and perception of FOP nutrition labelling schemes ${ }^{(33,42,51)}$. However, in the present work, support for nutritional warnings was not influenced by gender, age or socio-economic status. In particular, it is interesting to highlight that although women have been reported to be more interested in nutrition information than men ${ }^{(51,52)}$, in the present work, no gender differences were found in support for nutritional warnings, perceived healthfulness and willingness to use the warnings when purchasing foods.

Age and socio-economic status had a small effect on the perceived helpfulness of the warnings. Participants from low socio-economic status perceived the warnings as more helpful than participants from medium and high socio-economic status, which can be explained considering that people of low socio-economic status usually have lower nutritional knowledge and therefore face additional difficulties in understanding conventional nutrition information ${ }^{(53)}$. This suggests that the inclusion of nutritional warnings could contribute to reducing inequalities in the ability to make informed choices.

Age increased helpfulness perception of the warnings and disposition to take them into account when choosing foods. This result is consistent with the fact that interest in healthy eating or healthy interest usually increases with age $^{(54,55)}$ and responsibility for a family ${ }^{(56)}$. Therefore, young citizens (18-24 years old) are a demographic group that will need targeted communication along with general communication campaigns to motivate the use of nutritional warnings.

The present work showed that Uruguayan citizens show a positive attitude towards nutritional warnings and provided deep insights on how they interpret this FOP nutrition labelling scheme and how they expect to behave once they are introduced into the marketplace. However, one of the limitations of the study is that citizens' accounts may differ from their actual behaviour in a market setting. In their real life, citizens are expected to face several distractors which may decrease their attention to and use of nutritional warnings. Future research should look in detail into how nutritional warnings modify citizens' food choices under externally valid conditions.

\section{Conclusions}

Several conclusions can be drawn from the qualitative and quantitative findings. First, nutritional warnings would be largely accepted by Uruguayan citizens. Perception of the policy is in line with its intended function as a simple and easy FOP nutrition label to raise greater consciousness of food healthfulness. Second, consumers expressed willingness to alter their food choices by avoiding products with warnings primarily through substitution within the same food category. However, large category differences with regard to this impact should be expected. Third, few sociodemographic differences should be expected, indicating a potentially greater impact on lower socio-economic groups and for middle- and higher-aged consumers.

As an implication, the results suggest that policy makers should expect the policy to be well accepted among citizens on implementation. Therefore, nutritional warnings would likely be efficient in impacting healthy eating patterns in the Uruguayan population and reducing the intakes of sugar, fat, saturated fat and sodium. For industry stakeholders, the results imply that a profitable reaction might be to reformulate the products so that they show at best no or fewer warnings. However, the food industry should further explore category differences in consumer reaction to nutritional warnings. Policy makers should communicate the incentive of a business opportunity entailed in the reformulation, although category differences should be acknowledged. Such accompanying reformulation would further contribute to the improvement of the health status of the population.

Results underline that the core objective of accompanying policy efforts should be to increase health motivation and interest. Warnings should be accompanied by information and communication campaigns to increase awareness of nutritional warnings and encourage citizens to take them into account in their decision-making process. In addition, cues embedded in the point of purchase that encourage citizens to look at nutritional warnings could efficiently contribute to increase the efficiency of the policy, particularly in the case of citizens with low health motivation.

In summary, results from the present work stress the potential of nutritional warnings to discourage consumption of unhealthful products, confirming findings from recent experimental studies ${ }^{(4,46,57)}$. Further research should investigate the effect of nutritional warnings on consumer attention and purchase decisions in the actual market setting.

\section{Acknowledgements}

Financial support: The authors are indebted to Espacio Interdisciplinario (Universidad de la República) for financial support. The funder had no role in the design, analysis or writing of this article. Conflict of interest: None. Authorship: All authors contributed to the development of the research. G.A., L.A. and J.A.-W. analysed the data. G.A. and J.A.-W. wrote the first version of the manuscript, to which all other authors contributed. Ethics of human subject participation: This study was conducted according to the guidelines laid down in the Declaration of Helsinki and all procedures involving human subjects were approved by the Ethics Committee of the School of Chemistry of the Universidad de la República (Uruguay). Informed consent was obtained from all participants and formally recorded. 


\section{References}

1. Scrinis G \& Parker C (2016) Front-of-pack food labeling and the politics of nutritional nudges. Law Policy 39, 234-249.

2. Hawley KL, Roberto CA, Bragg MA et al. (2013) The science on front-of-package food labels. Public Health Nutr 16, 430-439.

3. Hodgkins C, Barnett J, Wasowicz-Kirylo G et al. (2012) Understanding how consumers categorise nutritional labels: a consumer derived typology for front-of-pack nutrition labelling. Appetite 59, 806-817.

4. Arrúa A, Machín L, Curutchet MR et al. (2017) Warnings as a directive front-of-pack nutrition labelling scheme: comparison with the Guideline Daily Amount and traffic-light systems. Public Health Nutr 20, 2308-2317.

5. Arrúa A, Curutchet MR, Rey N et al. (2017) Impact of frontof-pack nutrition information and label design on children's choice of two snack foods: comparison of warnings and the traffic-light system. Appetite 116, 139-146.

6. Ducrot P, Julia C, Méjean C et al. (2016) Impact of different front-of-pack nutrition labels on consumer purchasing intentions: a randomized controlled trial. Am J Prev Med $\mathbf{5 0}$, 627-636.

7. Julia C, Blanchet O, Méjean C et al. (2016) Impact of the front-of-pack 5-colour nutrition label $(5-\mathrm{CNL})$ on the nutritional quality of purchases: an experimental study. Int $J$ Behav Nutr Phys Act 13, 101.

8. Ni Mhurchu C, Volkova E, Jiang Y et al. (2017) Effects of interpretive nutrition labels on consumer food purchases: the Starlight randomized controlled trial. Am J Clin Nutr 105, 695-704.

9. Larsson I, Lissner L \& Wilhelmsen L (1999) The 'Green keyhole' revisited: nutritional knowledge may influence food selection. Eur J Clin Nutr 53, 776-780.

10. Food Standards Australia New Zealand (2015) Guide for Industry to the Health Star Rating Calculator (HSRC). Canberra: FSANZ.

11. Hercberg S (2013) Propositions pour un nouvel élan de la politique nutritionnelle française de santé publique dans le cadre de la Stratégie Nationale de Santé. 1ère Partie: Mesures concernant la Prévention nutritionnelle. http:// www.ladocumentationfrancaise.fr/var/storage/rapportspublics/144000068.pdf (accessed September 2017)

12. Corvalán C, Reyes M, Garmendia ML et al. (2013) Structural responses to the obesity and non-communicable disease epidemic: the Chilean law of food labelling and advertising. Obes Rev 14, 79-87.

13. Ministerio de Salud (2015) Decreto número 13, de 2015. Santiago: Ministerio de Salud.

14. Caro JC, Ng SW, Taillie LS \& Popkin BM (2017) Designing a tax to discourage unhealthy food and beverage purchases: the case of Chile. Food Policy 71, 86-100.

15. Monteiro CA, Cannon G, Levy RB et al. (2012) The Food System. Processing. The big issue for disease, good health, well-being. World Nutr 3, 527-569.

16. Pan American Health Organization (2015) Ultra-Processed Food and Drink Products in Latin America: Trends, Impact on Obesity, Policy Implications. Washington, DC: PAHO.

17. Monteiro CA, Moubarac JC, Cannon G et al. (2013) Ultraprocessed products are becoming dominant in the global food system. Obes Rev 14, 21-28.

18. Machín L, Giménez A, Curutchet MR et al. (2016) Motives underlying food choice for children and perception of nutritional information among low-income mothers in a Latin American country. J Nutr Educ Behav 48, 478-485.

19. Wojcicki JM \& Heyman MB (2013) Use of food labels, awareness of nutritional programmes and participation in the Special Supplemental Program for Women, Infants, and Children (WIC): results from the National Health and Nutrition
Examination Survey (2005-2006). Matern Child Nutr 9, 299-308.

20. Machín L, Cabrera M, Curutchet MR et al. (2017) Consumer perception of the healthfulness of ultra-processed products featuring different front-of-pack nutrition labeling schemes. J Nutr Educ Behav 49, 330-338.

21. Yoo JH, Machín L, Arrúa A et al. (2017) Children and adolescents' attitudes towards sugar reduction in dairy products. Food Res Int 94, 108-114.

22. Reisch LA (2004) Principles and visions of a new consumer policy. J Consum Policy 27, 1-42.

23. Cioffi CE, Levitsky DA, Pacanowski CR et al. (2015) A nudge in a healthy direction. The effect of nutrition labels on food purchasing behaviors in university dining facilities. Appetite 92, 7-14.

24. Graham DJ, Lucas-Thompson RG, Mueller MP et al. (2017) Impact of explained $v$. unexplained front-ofpackage nutrition labels on parent and child food choices: a randomized trial. Public Health Nutr 20, 774-785.

25. Mørk T, Grunert KG, Fenger M et al. (2017) An analysis of the effects of a campaign supporting use of a health symbol on food sales and shopping behaviour of consumers. BMC Public Health 17, 239.

26. Michie S, West R, Campbell R et al. (2015) ABC of Behaviour Change Theories (Behavior Change): An Essential Resource for Researchers, Policy Makers and Practitioners. London: Silverback Publishing.

27. Aschemann-Witzel J, Perez-Cueto FJA, Niedzwiedzka B et al. (2012) Lessons for public health from analysing commercial food marketing success factors: a case study. BMC Public Health 12, 139.

28. De Pelsmacker P, Geuens M \& Van den Bergh J (2017) Marketing Communications: A European Perspective, 6th ed. Harlow: Pearson Education Limited.

29. Brown KA, Timotijevic T, Barnett J et al. (2008) A review of consumer awareness, understanding and use of food-based dietary guidelines. Br J Nutr 106, 15-26.

30. Aschemann-Witzel J, Bech-Larsen T \& Capacci S (2016) Do target groups appreciate being targeted? An exploration of healthy eating policy acceptance. J Consum Policy 39, 285-306.

31. Mazzocchi M, Cagnone S, Bech-Larsen T et al. (2015). What is the public appetite for healthy eating policies? Evidence from a cross-European survey. Health Econ Policy Law 10, 267-292.

32. Cowburn G \& Stockley L (2005) Consumer understanding and use of nutrition labelling: a systematic review. Public Health Nutr 8, 21-28.

33. Visschers VHM, Hartmann C, Leins-Hess R et al. (2013) A consumer segmentation of nutrition information use and its relation to food consumption behaviour. Food Policy $\mathbf{4 2}$, $71-80$.

34. Ares G, Machín L, Girona A et al. (2017) Comparison of motives underlying food choice and barriers to healthy eating among low medium income consumers in Uruguay. Cad Saude Publica 33, e00213315.

35. Hough G \& Sosa M (2015) Food choice in low income populations: a review. Food Qual Prefer 40, 334-342.

36. Ministerio de Salud Pública (2015) $2^{a}$ Encuesta Nacional de Factores de Riesgo de Enfermedades no Transmisibles. Montevideo: Ministerio de Salud Pública.

37. Ministerio de Industria, Energía y Minería (2017) Consulta pública sobre proyecto de decreto relativo a Rotulado de alimentos envasados. http://www.miem.gub.uy/-/consultapublica-sobre-proyecto-de-decreto-relativo-a-rotulado-dealimentos-envasados (accessed August 2017).

38. Grupo Radar (2017) El Perfil del Internauta Uruguayo. Montevideo: Grupo Radar. 
39. Perera M \& Cazulo P (2016) Índice de Nivel Socioeconómico. Montevideo: Centro de Investigaciones Económicas.

40. Krippendorff K (2004) Content Analysis: An Introduction to Its Methodology, 2nd ed. Thousand Oaks, CA: SAGE Publications, Inc.

41. Millstone E \& Lobstein T (2007) The PorGrow project: overall cross-national results, comparisons and implications. Obes Rev 8, 29-36.

42. Grunert KG \& Wills JM (2007) A review of European research on consumer response to nutrition information on food labels. J Public Health 15, 384-399.

43. Kelly B, Hughes C, Chapman K et al. (2009) Consumer testing of the acceptability and effectiveness of front-of-pack food labelling systems for the Australian grocery market. Health Promot Int 24, 120-129.

44. Pettigrew S, Talati Z, Miller C et al. (2017) The types and aspects of front-of-pack food labelling schemes preferred by adults and children. Appetite 209, 115-123.

45. Valdebenito Verdugo M, Labrín Elgueta JM, León Perath V et al. (2017) Informe de Resultados: Descripción de las Percepciones y Actitudes de los/as Consumidores Respecto a las Medidas Estatales en el Marco de la Implementación del Decreto 13/15. Santiago: Demoscopica.

46. Ares G, Aschemann-Witzel J, Curutchet MR et al. (2018). Nutritional warnings and product substitution or abandonment: policy implications derived from a repeated purchase simulation. Food Qual Prefer 65, 40-48.

47. He FJ, Brinsden HC \& Macgregor GA (2014) Salt reduction in the United Kingdom: a successful experiment in public health. J Hum Hypertens 28, 345-352

48. Lima M, Ares G \& Deliza R (2018) How do front of pack nutrition labels affect healthfulness perception of foods targeted at children? Insights from Brazilian children and parents. Food Qual Prefer 64, 111-119.

49. Maubach N, Hoek J \& McCreanor T (2009) An exploration of parents' food purchasing behaviours. Appetite $\mathbf{5 3}$, 297-302.

50. Tonkin E, Wilson AM, Coveney J et al. (2015) Trust in and through labelling - a systematic review and critique. $\mathrm{Br}$ Food J 117, 318-338.

51. Gregori D, Ballali S, Vögele C et al. (2014) Evaluating food front-of-pack labelling: a pan-European survey on consumers' attitudes toward food labelling. Int J Food Sci Nutr 65, 177-186.

52. Campos S, Doxey J \& Hammond D (2011) Nutrition labels on pre-packaged foods: a systematic review. Public Health Nutr 14, 1496-1506.

53. Drichoutis AC, Lazaridis P \& Nayga RM. Jr (2005) Nutrition knowledge and consumer use of nutritional food labels. Eur Rev Agric Econ 32, 93-118.

54. Lumbers M \& Raats M (2006) Food choices in later life. In The Psychology of Food Choice, pp. 289-310 [R Sheperd and $M$ Raats, editors]. Wallingford: CABI Publishing.

55. Grunert KG, Fernández-Celemin L, Wills JM et al. (2010) Use and understanding of nutrition information on food labels in six European countries. J Public Health 18, 261-277.

56. Aschemann-Witzel J (2013) Danish mothers' perception of the healthiness of their dietary behaviors during transition to parenthood. J Fam Issues 34, 1335-1355.

57. Machín L, Aschemann-Witzel J, Curutchet MR et al. (2018) Does front-of-pack nutrition information improve consumer ability to make healthful choices? Performance of warnings and the traffic light system in a simulated shopping experiment. Appetite 121, 55-62 